\title{
HIPERPLASIA ENDOMETRIAL CÍSTICA E PIOMETRA ABERTA PÓS- PARTO EM UMA CADELA: RELATO DE CASO
}

\section{ARTIGO ORIGINAL}

SILVA, Laurenh da ${ }^{1}$, AUST, Ana Carolina Camargo de Oliveira ${ }^{2}$

SILVA, Laurenh da. AUST, Ana Carolina Camargo de Oliveira. Hiperplasia endometrial cística e piometra aberta pós-parto em uma cadela: relato de caso. Revista Científica Multidisciplinar Núcleo do Conhecimento. Ano 05, Ed. 09, Vol. 02, pp. 101-108. Setembro de 2020. ISSN: 2448-0959, Link de acesso: https://www.nucleodoconhecimento.com.br/veterinaria/hiperplasia-

endometrial, DOI: 10.32749/nucleodoconhecimento.com.br/veterinaria/hiperplasiaendometrial

\section{RESUMO}

A Hiperplasia Endometrial Cística (HEC) é um fator predisponente ao desenvolvimento de infecções uterinas. A piometra, consequência da hiperplasia endometrial cística, é frequente na rotina do médico veterinário, apresentando importância clínica. O objetivo deste trabalho, é estudar a patologia envolvida na retenção placentária em associação com a ocorrência da piometra, a qual se resume em um acúmulo de secreção purulenta no interior do útero, resultado de interação entre estrógeno e progesterona, complicada por contaminação bacteriana ascendente. A retenção placentária pode ser vista como fator desencadeante para a infecção bacteriana uterina, mas é pouco falado sobre a sua associação com a piometra. Nos métodos de diagnóstico inclui-se ultrassom, hemograma e bioquímico. O tratamento é clínico sintomático, mas só há a cura quando é feito a retirada do

\footnotetext{
${ }^{1}$ Tecnóloga em Meio Ambiente; Graduanda em Medicina Veterinária.

${ }^{2}$ Orientadora. Doutorado em andamento em Ciência Animal. Mestrado em Ciências Veterinárias. Graduação em Medicina Veterinária.
}

RC: 59358

Disponível em: https://www.nucleodoconhecimento.com.br/veterinaria/hiperplasia- 
foco de infecção. Concluiu-se que a retenção placentária pode ser um foco de infecção bacteriana que aliado à ação do estrógeno e da progesterona, resultará em piometra.

Palavras-chave: complexo endometrial cístico, endométrio, infecção uterina.

\section{INTRODUÇÃO}

A piometra é uma doença uterina observada principalmente durante a fase de diestro ou ínicio do anestro do ciclo estral. Hiperplasia endometrial cística (HEC) mediada pela progesterona (P4) e potencialmente agravada pelo estrógeno (E2) é sugerida como lesão inicial de piometra em cadelas (VOLPATO et al., 2018), tendo muitas vezes bactérias como coadjuvantes no processo. Inicialmente ocorre uma resposta fisiológica exagerada do endométrio à progesterona, e as glândulas endometriais tornam-se císticas e repletas de líquido (BARNI et al., 2013). De acordo com Chen et al. (2007), o aparecimento da enfermidade está relacionado com a idade da paciente, quantidade de ciclos estrais e alterações ovarianas presentes, e aparentemente não há qualquer predisposição racial. Sob influência estrogênica, a cervix se abre, o que permite a entrada de bactérias da flora normal da vagina para dentro da luz uterina, esse hormônio aumenta o número de receptores de progesterona no endométrio, após a ovulação, e a progesterona que se liga ao seu receptor situado no endométrio promove o aumento da quantidade $e$ atividade das glândulas endometriais, que por sua vez, em resposta da super estimulação (OLIVEIRA, 2007), resulta no desenvolvimento de uma hiperplasia endometrial cística com consequente acúmulo de líquidos nas glândulas endometriais e na luz uterina (OLIVEIRA et al, 2017), diminuindo a contração do miométrio e a resposta leucocitária intrauterina e, desta maneira, predispondo a infecção bacteriana. O produto de secreção das glândulas, inicialmente estéril, contém nutrientes e pH favoráveis ao crescimento bacteriano, e com a diminuição da resposta inflamatória o processo se instala (FORESTI, 2017).

RC: 59358

Disponível em: https://www.nucleodoconhecimento.com.br/veterinaria/hiperplasia- 
Clinicamente, a piometra pode se apresentar com a cérvix fechada e com sinais clínicos agudos e graves. Em casos nos quais a cérvix está aberta e drenando conteúdo purulento, os sinais clínicos podem ser de menor gravidade (EVANGELISTA et al., 2011). Nos casos de piometra de cérvix fechada, a mortalidade é mais alta, pois apresenta sinais clínicos agudos e graves (EVANGELISTA et al., 2011) pois não há drenagem do fluído (Pereira e Silva, 2016) podendo haver ruptura do útero em palpação abdominal, devido ao seu grau de distensão (OLIVEIRA, 2007). Os sinais clínicos da piometrite incluem letargia, poliúria, polidipsia, vômito, diarreia e algumas vezes secreção vaginal (BARNI et al., 2013). O diagnóstico da doença deve basear-se na anamnese, nos sinais clínicos, na radiografia ou ultrassonografia abdominais. Devem ser realizados também o hemograma, perfil bioquímico sérico e urinálise para avaliar alterações da função renal e detecção de anormalidades metabólicas associadas à sepse (EVANGELISTA et al., 2011). O principal tratamento empregado é a ováriosalpingohisterectomia (BARNI et al., 2013).

\section{RELATO DE CASO}

Foi atendida em uma clínica veterinária em Curitiba, uma cadela, Shih Tzu, de 4 anos de idade, 5,3 quilos, com queixas de apatia e anorexia.

Durante a anamnese, foi relatado que a paciente passou por um parto de uma ninhada há cerca de uma semana. Relatou-se após o parto episódios de diarreia, secreção vulvar com coloração amarronzada e hipertermia. Durante o exame físico, foi constatada apatia e anorexia, frequência cardíaca de $142 \mathrm{bpm}$, frequência respiratória de 28 mvpm e temperatura retal de $39,5^{\circ} \mathrm{C}$.

A paciente foi submetida aos exames complementares, dentre eles hemograma, dosagem bioquímica de bilirrubinas e ultrassom abdominal. O exame ultrassonográfico de abdômen sugestionou processo inflamatório com base na imagem do baço ("ecogenicidade diminuída, com tamanho, forma e contorno

RC: 59358

Disponível em: https://www.nucleodoconhecimento.com.br/veterinaria/hiperplasia- 
preservados"), sugestão de enterite/colite com base na imagem das alças intestinais e de cólon ("alças intestinais preenchidas por conteúdo gasoso e heterogêneo, com espessura de $0,16 \mathrm{~cm}$ e estratificação de paredes sem alterações, porém com espessamento da camada mucosa, nos segmentos possíveis de avaliação. Cólon com presença de conteúdo fluído heterogêneo e parede espessada"); diagnóstico de gastrite, retardo de involução uterina pela imagem de cornos e corpo uterino ("distendidos por conteúdo anecóico, parede espessada com múltiplas microestruturas anecóicas arredondadas entremeadas em parede. Em corno uterino esquerdo, estendendo-se até região do corpo, observa-se presença de material ecogênico, irregular com presença de conteúdo anecóico. Corno uterino esquerdo medindo aproximadamente $2,19 \mathrm{~cm}$, corno direito $0,54 \mathrm{~cm}$ e corpo uterino $1,01 \mathrm{~cm}$. Aumento da ecogenicidade mesentérica adjacente aos cornos e corpo uterino"), onde a presença de material ecogênico indica processo inflamatório associado a hiperplasia endometrial cística; também não foi descartada a possibilidade de retenção placentária. Também foi observado a presença de peritonite focal.

Segundo Capuzzi (2000), a metrite (inflamação do útero), que resulta da invasão bacteriana ao útero, secundário neste caso, à retenção placentária, pode ser fator predisponente para a piometra e até mesmo à sepse. Os sinais clínicos e achados de exames complementares da paciente relatada, confirmam com os dados referentes a piometra comumente conhecida, relacionada a ciclo estral, sinais os quais dependem primariamente da eficiência da cérvix em permitir a drenagem do fluído purulento (CONRADO, 2009). Alterações em hemograma e leucograma, também entraram em acordo com os dados relatados na literatura sobre piometra.

O hemograma apresentou alterações relacionadas ao eritrograma, com diminuição dos valores de hemoglobina 11,3 g/dL (12 a $18 \mathrm{~g} / \mathrm{dL}$ ), hematócrito $32 \%$ (37 a 53\%) e valor corpuscular médio 57,14 fL (60 a $77 \mathrm{fL})$, indicando uma anemia não regenerativa, podendo ser resultado de deficiência nutricional por vitamina B12 ou ácido fólico, considerando o aumento da demanda energética e nutricional pela

RC: 59358

Disponível em: https://www.nucleodoconhecimento.com.br/veterinaria/hiperplasia- 
gestação e amamentação, mas também, em um estudo, a anemia pré-operatória foi hipoteticamente explicada pela perda sanguínea para o lúmen uterino associada à depressão tóxica da medula óssea (CONRADO, 2009). No leucograma havia aumento de leucócitos totais $20.900 / \mathrm{mm}^{3}$ (6.000 a 17.000) pelo aumento de bastonetes $3762 / \mathrm{mm}^{3}$ ( 0 a $510 / \mathrm{mm}^{3}$ ), demonstrando um desvio à esquerda regenerativo, indicando um processo inflamatório provavelmente de origem infecciosa. O plasma apresentava lipemia que pode ocorrer pela falta de jejum alimentar ou anorexia prolongada fazendo mobilização de lipídios de reserva como fonte de energia. Também foi observado a presença de neutrófilos com alterações tóxicas, indicando gravidade de infecção.

A dosagem de fosfatase alcalina (303,7 UI/L) se apresentou com valores acima dos de referência (20 a $150 \mathrm{UI} / \mathrm{L}$ ), que pode ser justificado pela gestação recente, uma vez que a placenta produz uma fração desta enzima. Mas também pode se atribuir ao catabolismo ou possível lesão hepática gerada pela doença. O valor da ureia $(89,6 \mathrm{md} / \mathrm{dl}$ ) acima dos valores de referencia (10 a $60 \mathrm{mg} / \mathrm{dl}$ ) também se apresentou elevado, justificado pelo fato de cadelas com piometra podem desenvolver insuficiência renal causada secundária a glomerulonefrite secundária ao depósito de complexos imunes. Esse aumento de ureia também pode ser causado por azotemia pré-renal como consequência de desidratação. Constou-se como observações: soro e plasma lipêmico.

O diagnóstico final de piometra foi dado a partir da associação do histórico clínico, anamnese e exames complementares.

O prognóstico dos animais acometidos depende muito do comprometimento do estado geral do animal, principalmente pensando na função renal e hepática, evolução da doença e da toxicidade sistêmica (BIANCHI e BERTOTTI, 2017). O prognostico do tratamento cirúrgico, depende de alguns fatores, tais como, o estado geral do paciente, do comprometimento ou não de outros sistemas, de que não haja

RC: 59358

Disponível em: https://www.nucleodoconhecimento.com.br/veterinaria/hiperplasia- 
contaminação transoperatória e do controle da sepse. Não havendo intercorrências, o prognostico é favorável promovendo a cura sem recidivas (FORESTI, 2017).

A paciente foi internada, realizado tratamento farmacológico com Dipirona IV com frequência TID; Ranitidina IV com frequência BID; Ondansentrona com frequência TID; Ampicilina associado com Sulbactam Sódico IV com frequência TID; Tramadol IV com frequência TID. Ao se estabelecer o diagnóstico definitivo, foi realizado o procedimento de ováriosalpingo-histerectomia.

De forma geral, a anamnese, resultados de exames complementares e sinais clínicos vistos entraram em acordo com os observados em literatura. A anamnese, assim como os sinais clínicos apresentados pelo animal, são usados no diagnóstico da piometra. A suspeita é levantada em qualquer cadela que não tenha sido esterilizada e que apresente anormalidades clínicas e laboratoriais compatíveis com a enfermidade (CONRADO, 2009). No exame físico de animais acometidos por piometrite, o corrimento vaginal sanguinolento purulento poderá estar presente se a cérvix estiver aberta. a temperatura retal em ambas as apresentações da doença pode estar normal ou aumentada em decorrência da infecção uterina, infecção bacteriana secundária, septicemia ou toxemia (BARNI et al, 2013). O útero dilatado apresenta uma imagem ultra-sonográfica de uma estrutura tubular bem definida com diâmetro entre 0,5 a $4,0 \mathrm{~cm}$, o conteúdo luminal uterino apresenta menos ecogenicidade que a parede, com cintilações ecogênicas bem evidentes (LIMA, 2009). O achado de hemograma mais comum em cadelas e gatas é uma neutrofilia com desvio à esquerda, a sepse pode ocasionar alterações tóxicas nos neutrófilos. O eritrograma possivelmente evidenciará anemia normocítica normocrônica (nãoregenerativa, onde no caso relatado foi visto anemia microcítica hipocrômica. Além disso, sinais clínicos como depressão, diarreia, vômito, polidipsia e poliúria auxiliam na definição do diagnóstico. Os sinais clínicos mais comuns encontrados em piometrites de cérvix aberta, além da secreção vaginal de mau odor e coloração sanguinolenta a mucopurulenta, são letargia, depressão, inapetência, anorexia,

RC: 59358

Disponível em: https://www.nucleodoconhecimento.com.br/veterinaria/hiperplasia- 
poliúria, polidipsia, vômito e diarreia. Primeiramente 0 paciente deve ser estabilizado, iniciando-se a antibioticoterapia, e a fluidoterapia intensiva, que corrigirá a azotemia e a perfusão tecidual e melhorará a função renal, além de melhorar o prognóstico do caso (BARNI et al, 2013) e também neste relato foi adicionado medicação para controle de dor, e também para o sistema gastrintestinal, diminuindo o desconforto da paciente. A ovariosalpingohisterectomia $(\mathrm{OSH})$ é o tratamento mais recomendado porque controla a origem da sepse ao remover permanentemente o local da infecção e os animais submetidos ao procedimento rapidamente recuperam-se da cirurgia (FORESTI, 2017).

\section{CONCLUSÃO}

De acordo com o caso estudado, assimilando com os dados encontrados em literatura e por estudos da patologia da piometra, a retenção de placenta é um fator desencadeante para a infecção bacteriana, onde o ciclo estral é visto como fator prédisponente e a situação de pós-parto, um fator facilitador.

\section{REFERÊNCIAS}

BARNI, B. et al. Hiperplasia endometrial cística em cadelas e gatas: revisão de literatura. Publicado em Ciência Animal 23(1):09-19, 2013. Disponível em <http://www.uece.br/cienciaanimal/dmdocuments/Artigo2_2013_1.pdf>Acesso em 26/05/2020>

BIANCHI, R., Bertotti, S. C. (2017). PIOMETRA EM CADELAS. Anuário Pesquisa E Extensão Unoesc Xanxerê, 2, e13732. Disponível em <https://unoesc.emnuvens.com.br/apeux/article/view/13732>

CAPUZZI, J. Canine Reproduction in 30th Annual Canine Symposium in Bellwether Magazine. 1 edition, pag 10-17. University of Pennsylvania. January 29, 2000. Disponível em

RC: 59358

Disponível em: https://www.nucleodoconhecimento.com.br/veterinaria/hiperplasiaendometrial 
<https://repository.upenn.edu/cgi/viewcontent.cgi?article=1878\&context=bellwether> Acesso em 26/05/2020.

CHEN, R. F. F. et al. Piometra aberta em uma cadela de 10 meses. Publicado em Revista Acadêmica Ciência Animal. V. 5, n. 3, 2007. Disponível em < https://periodicos.pucpr.br/index.php/cienciaanimal/article/view/10140/9555> Acesso em 24/06/2020.

CONRADO, F. Aspectos clínico-patológicos da piometra. Porto Alegre: UFRGS, 2009/2.

Disponível em <https://www.lume.ufrgs.br/bitstream/handle/10183/22930/000737603.pdf?seque nce $=1$ \&isAllowed $=\mathrm{y}>$ Acesso em 26/05/2020.

EVANGELISTA, L.; et al. Perfil clínico e laboratorial de gatas com piometra antes e após ovário-histerectomia. Publicado em Revista Brasileira de Reprodução Animal, Belo Horizonte, v.35, n.3, p.347-351, jul./set. 2011. Disponível em $<$ http://www.cbra.org.br/pages/publicacoes/rbra/v35n3/pag347-351.pdf > Acesso em 26/05/2020.

FORESTI, L.T. Complexo endometrial cistico e piometra em gatas: revisão de literatura e estudo sobre a população microbiana e sensibilidade aos fármacos antimicrobianos. Porto Alegre: UFRGS, 2017. Disponível em <http://hdl.handle.net/10183/171006> Acesso em 01/06/2020.

LIMA, L. Piometra em cadelas. Publicado em Faculdades Metropolitanas Unidas, São Paulo, 2009. Disponível em <http://arquivo.fmu.br/prodisc/medvet//rsl.pdf> Acesso em 26/05/2020.

OLIVEIRA, I.; et al. Piometra em gata - revisão de literatura. Publicado em Almanaque de Medicina Veterinária e Zootecnia, Abril de 2017, páginas 1 a 11. Disponível em

RC: 59358

Disponível em: https://www.nucleodoconhecimento.com.br/veterinaria/hiperplasiaendometrial 
<http://www.fio.edu.br/revistamv/arquivos/v5/PIOMETRA\%20EM\%20GATA\%20\%20REVIS\%C3\%83O\%20DE\%20LITERATURA.pdf> Acessado em 26/05/2020.

OLIVEIRA, K.; Complexo hiperplasia endometrial cística. Publicado em Acta Scientiae Veterinariae. 35(Supl 2): s270-s272, 2007. Disponível em $<$ http://www.ufrgs.br/actavet/35-suple-2/19-ANCLIVEPA.pdf> Acessado em 26/05/2020.

PEREIRA, M.S.R., Silva P.R. Piometra em cadela. Publicado em ANAIS do ICESP Promove SIMPÓSIO. Disponível em < http://nippromove.hospedagemdesites.ws/anais_simposio/arquivos_up/documentos/ artigos/179b90b58c8b6b02bf61b54c2cbb471e.pdf> Acessado em 24/06/2020.

VOLPATO, R. et al. Infiltrado leucocitário em cérvix de cadelas com piometra aberta e fechada. Publicado em Revista Científica de Medicina Veterinária. Ano X, N. 30, Periódico Semestral, Janeiro de 2018. Disponível em < http://faef.revista.inf.br/imagens_arquivos/arquivos_destaque/qWJrBlubdAt9IIP_2018 -7-6-10-48-37.pdf> Acessado em 24/06/2020.

Enviado: Abril, 2020.

Aprovado: Setembro, 2020.

RC: 59358

Disponível em: https://www.nucleodoconhecimento.com.br/veterinaria/hiperplasiaendometrial 